\title{
Short- and long-term outcomes after hemihepatectomy for perihilar cholangiocarcinoma: does left or right side matter?
}

\author{
Lotte C. Franken ${ }^{1}$, Pim B. Olthof ${ }^{1,2}$, Joris I. Erdmann ${ }^{1}$, Otto M. van Delden ${ }^{3}$, Joanne Verheij ${ }^{4}$, \\ Marc G. Besselink ${ }^{1}$, Olivier R. Busch ${ }^{1}$, Thomas M. van Gulik ${ }^{1}$
}

${ }^{1}$ Department of Surgery, Cancer Center Amsterdam, Amsterdam UMC, University of Amsterdam, The Netherlands; ${ }^{2}$ Department of Surgery, Erasmus Medical Center, Erasmus University, Rotterdam, The Netherlands; ${ }^{3}$ Department of Radiology and Nuclear Medicine, Amsterdam UMC, University of Amsterdam, Amsterdam, The Netherlands; ${ }^{4}$ Department of Pathology, Cancer Center Amsterdam, Amsterdam UMC, University of Amsterdam, Amsterdam, The Netherlands

Contributions: (I) Conception and design: OR Busch, TM van Gulik, MG Besselink; (II) Administrative support: LC Franken, PB Olthof; (III) Provision of study materials or patients: JI Erdmann, J Verheij, OM van Delden, MG Besselink, OR Busch, TM van Gulik; (IV) Collection and assembly of data: LC Franken, PB Olthof; (V) Data analysis and interpretation: LC Franken, PB Olthof, JI Erdmann, OM van Delden, J Verheij; (VI) Manuscript writing: All authors; (VII) Final approval of manuscript: All authors.

Correspondence to: Miss Lotte C. Franken, MD. Department of Surgery, Cancer Center Amsterdam, Amsterdam UMC, University of Amsterdam, PO Box 22660, 1100 DD, Amsterdam, The Netherlands. Email: 1.c.franken@amsterdamumc.nl.

Background: The only potentially curative option for patients with perihilar cholangiocarcinoma (PHC) is resection, typically an extrahepatic bile duct resection in combination with (extended) liver resection. Complications such as bile leakage and liver failure have been suggested to be more common after rightsided resections compared to left-sided resections, whilst superior oncological outcomes have been reported after right-sided resections. However, data on outcomes after right-sided or left-sided liver resections in $\mathrm{PHC}$ are scarce. Therefore, we aimed to investigate short- and long-term outcomes after left and right hemihepatectomy in patients with PHC.

Methods: In this retrospective study, patients undergoing major liver resection for suspected $\mathrm{PHC}$ in a tertiary center between 2000-2018 were included. Patients who had undergone left-sided resections were compared to patients with right-sided resections in terms of complications (90-day mortality, overall and severe morbidity and specific complications). For long-term outcomes, only patients with pathologically proven PHC were included in the survival analysis.

Results: A total of 178 patients undergoing hemihepatectomy for suspected $\mathrm{PHC}$ were analysed, including 76 left-sided and 102 right-sided resections. Overall 90-day mortality was 14\% (24 out of 178), with no significant difference after left-sided resection (11\%; 8 out of 76$)$ versus right-sided resection $(16 \% ; 16$ out of 102) ( $\mathrm{P}=0.319)$. Severe morbidity (Clavein Dindo $\geq 3$ ) was also comparable in both groups: $54 \%$ versus $61 \%(\mathrm{P}=0.361)$. No differences in specific complications including bile leakage were observed, although liver failure appeared to occur more frequently after right hemihepatectomy (22\% versus $11 \%, \mathrm{P}=0.052$ ). Fiveyear overall survival for pathologically proven PHC, excluding in-hospital mortality, did not differ; $43.7 \%$ after left-sided resection $v$ s. and $38.2 \%$ after right-sided resection $(\mathrm{P}=0.553)$.

Conclusions: Both short- and long-term outcomes between patients undergoing left and right hemihepatectomy for PHC were comparable. Post-hepatectomy liver failure was more common after rightsided resection.

Keywords: Perihilar cholangiocarcinoma (PHC); hepatectomy; outcomes; mortality; survival

Submitted Dec 28, 2019. Accepted for publication May 11, 2020.

doi: $10.21037 /$ hbsn-19-948

View this article at: http://dx.doi.org/10.21037/hbsn-19-948 


\section{Introduction}

Surgical treatment for perihilar cholangiocarcinoma (PHC) typically entails extrahepatic bile duct resection combined with (extended) hemihepatectomy. Although this approach offers the only chance of cure, the required complex procedures are known for their high risk of postoperative complications (1). The predominant, anatomic location of the tumour and vascular involvement determine whether patients undergo a right-sided or left-sided liver resection (2). In most reports dealing with curative-intent resection of PHC, outcomes after right-sided or left-sided liver resections for suspected PHC are combined. Some authors, however, studied whether outcomes after right-sided resections may be different compared to left-sided resections (3-7). Although some of these focus on Bismuth-Corlette type III tumors (4) or only compare right hepatectomy to extended left hepatectomy (6), others include all patients presenting with $\mathrm{PHC}$ requiring major liver resection $(5,7)$. Interestingly, a study by Ratti and colleagues showed significantly higher mortality and morbidity rates after right-sided resections compared to left-sided resections, including higher incidence of postoperative liver failure (5). Postoperative liver failure, one of the most important complications often leading to postoperative mortality after major liver resection, is thought to occur more often after right hemihepatectomy, considering the larger volume of the right hemi-liver leaving a relatively small liver remnant. However, technical advantages of right hemihepatectomy have also been described and the longer left hepatic duct has been considered to result in a higher rate of tumor negative margins after right-sided resections, theoratically offering an oncological benefit. The aforementioned study by Ratti showed a significantly higher 5 -year overall survival in 61 patients undergoing right-sided resections (42.8\%) compared to 44 patients undergoing left-sided resections $(35.2 \%)(5,8)$.

Another factor, related to left or right-sided resections is the performance of concomitant portal vein resection and subsequent reconstruction (PVR). PVR is often required to achieve R0 resection in PHC (9-11). The greater length of the left portal vein facilitates reconstruction and may therefore be preferably performed in combination with rightsided resections. This may therefore influence outcomes of right- versus left-sided resection. After (extended) right hemihepatectomy, the biliary-enteric anastomosis is usually straightforward, using the cut segmental ducts of B4, B2 and $\mathrm{B} 3$ or only B2/3 for the jejunal anastomosis. After a left-sided resection, the proximal segmental ducts show more variation and usually require multiple anastomoses potentially leading to more biliary complications (12).

To date, literature on outcomes after right- and leftsided resections in PHC is conflicting and available data are limited $(3,4)$. Therefore, we aimed to compare outcomes after left or right hemihepatectomy in our series of patients undergoing resection for suspected $\mathrm{PHC}$. We present the following article in accordance with the STROBE reporting checklist (available at https://hbsn.amegroups.com/article/ view/10.21037/hbsn-19-948/rc).

\section{Methods}

Patients undergoing resection for hilar tumors suspected of PHC in a single tertiary center were retrieved from a prospectively maintained database. The study was conducted in accordance with the Declaration of Helsinki (as revised in 2013). The Institutional Medical Ethics Committee waived the need for individual informed consent and ethical approval (W19_408). Consecutive patients undergoing resection of the extrahepatic bile duct in combination with left or right hemihepatectomy for suspected PHC between 2000 and 2018 were included. Patients undergoing external bile duct resection only, or combined with central or minor liver resections were excluded.

\section{Baseline and surgical variables}

Work-up of patients undergoing resection for PHC in our center has been described previously (13). Baseline characteristics were collected including age, sex, BismuthCorlette type, preoperative biliary drainage and portal vein embolization. Additionally, intraoperative variables such as PVR and reconstructions and hepatic artery reconstructions were collected. PVR and reconstruction was performed selectively when involved. Patients undergoing left-sided resection were compared to patients undergoing right-sided resections.

\section{Short-term outcomes}

For short-term outcomes, all patients undergoing external bile duct resection with hemihepatectomy on the suspicion of PHC were analysed, including patients with different diagnosis at final pathological assessment. Primary outcomes were severe morbidity (Clavien-Dindo grade $\geq 3$ ) and 90 day mortality. Secondary outcomes were overall morbidity 
(including Clavien-Dindo grade 1 and 2), length of hospital stay and types of complications including bile leakage, liver failure and haemorrhage (all graded by the International Study Group of Liver Surgery (ISGLS) grading system, with grade B and C considered clinically relevant) (14-16). Recently, all pathology reports were revised according to the International Collaboration on Cancer Reporting (ICCR) guideline $(17,18)$. According to this guideline, a margin of $<1 \mathrm{~mm}$ at any resection plane, including the periductal dissection plane, was considered as residual disease.

\section{Long-term outcomes}

For oncological outcomes, only patients with pathologically proven PHC were included in the analysis. Primary outcome was overall survival, calculated as survival in months after surgery. Surviving PHC-patients were censored at last date of follow-up. Recurrence was defined as local (hilar, at the hepaticojejunostomy or local lymph nodes) or distant recurrence (distant lymph nodes, liver, lung or other metastases).

\section{Statistics}

Descriptive statistics were used to describe the data. Continuous variables following a normal distribution were described by mean and standard deviation or median and interquartile range in case of a non-normal distribution. Kaplan-Meier method was used to calculate overall survival and the reverse Kaplan-Meier based method was used to calculate median follow up. Comparison between the two groups were analysed using chi-square or Fisher exact test for proportions, $t$-test for means and Mann-Whitney Test for medians. Survival curves were compared using the log-rank test. Predictors of overall survival (excluding postoperative mortality) were analysed using univariate and multivariate Cox-regression analysis. Factors with $\mathrm{P}$ values $<0.200$ at univariate analysis were included in the multivariate analysis, as well as the two variables of interest in this study (right versus left hemihepatectomy and with/ without portal vein reconstruction). Statistical analyses were performed using SPSS version 25.0. Survival curves were displayed using GraphPad Prism 8.

\section{Results}

\section{Patients and procedures}

A total of 178 patients undergoing hemihepatectomy with external bile duct resection for suspected PHC were identified, of which 76 patients underwent left hemihepatectomy and 102 patients underwent right hemihepatectomy. Baseline characteristics of all patients, and of patients undergoing left and right-sided resections are listed in Table 1. Bismuth-Corlette type IV tumors

Table 1 Baseline characteristics of all patients left- or right-sided liver resection for suspected PHC

\begin{tabular}{|c|c|c|c|c|}
\hline Characteristic & All suspected PHC $(n=178)$ & Left-sided liver resection $(n=76)$ & Right-sided liver resection ( $n=102)$ & $P$ value \\
\hline Female, $\mathrm{n}[\%]$ & 69 [39] & 31 [41] & $38[37]$ & 0.632 \\
\hline Age, mean [SD] & $63[10]$ & 64 [9] & 62 [11] & 0.219 \\
\hline ASA, $n[\%]$ & & & & 0.945 \\
\hline 1 & 34 [19] & 14 [19] & $20[20]$ & \\
\hline II & $117[66]$ & $51[67]$ & 66 [65] & \\
\hline III & 27 [15] & $11[15]$ & $16[16]$ & \\
\hline ECOG performance state, $n[\%]$ & & & & 0.525 \\
\hline 0 & $122[68]$ & 54 [71] & $68[67]$ & \\
\hline 1 & $42[24]$ & $16[21]$ & $26[26]$ & \\
\hline 2 & $12[7]$ & $6[8]$ & $6[6]$ & \\
\hline 3 & $2[1]$ & 0 & 2 [2] & \\
\hline Tumor diameter, median [IQR] & $30[20-40]$ & 30 [21-41] & $25[20-40]$ & 0.221 \\
\hline
\end{tabular}

Table 1 (continued) 
Table 1 (continued)

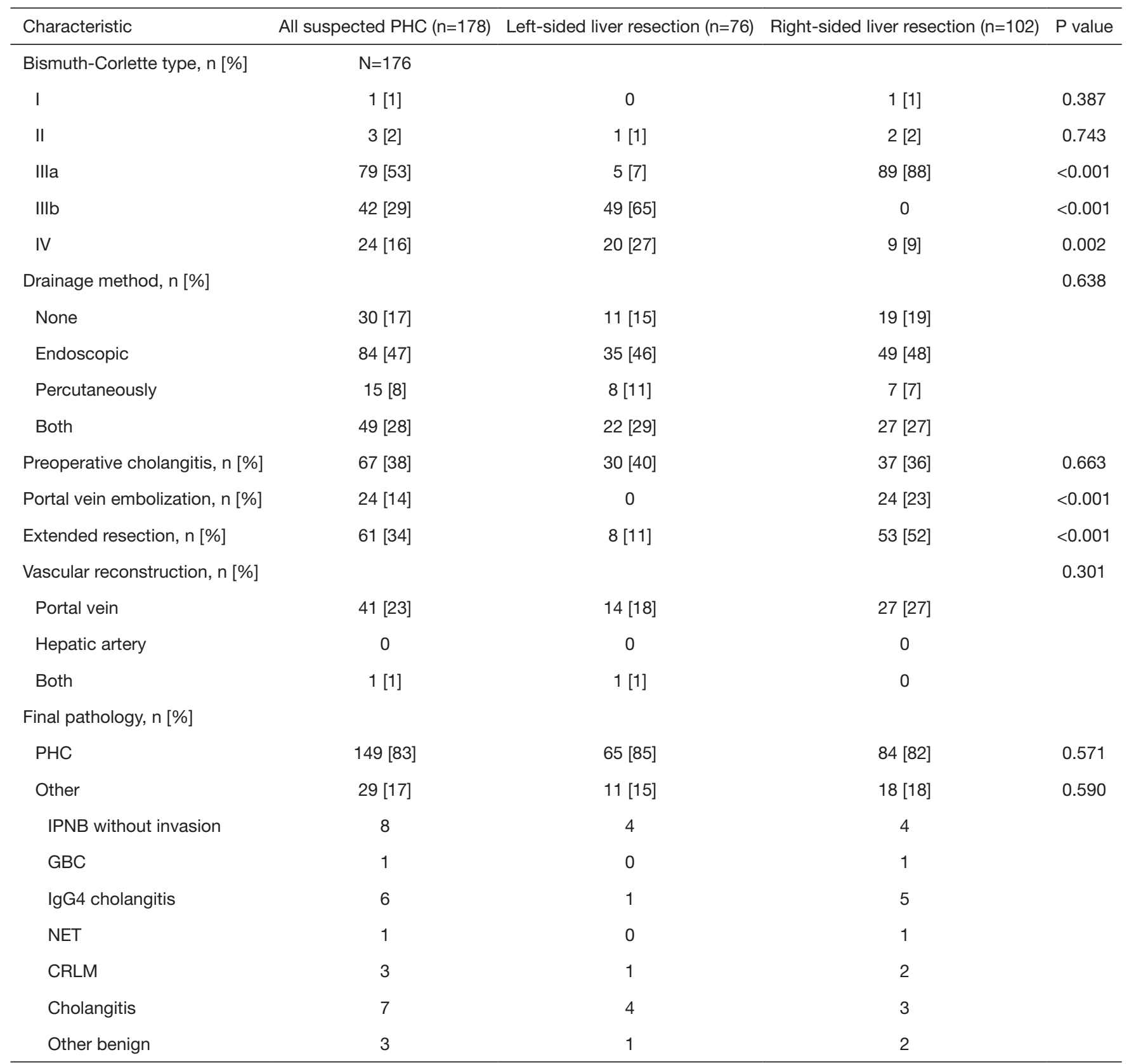

PHC, perihilar cholangiocarcinoma; IPNB, intraductal papillary neoplasms of the bile duct; NET, neuroendocrine tumor; CRLM, colorectal liver metastases; GBC, gallbladder carcinoma.

and extended resections were common among patients undergoing right compared to patients undergoing left hemihepatectomy. Portal vein embolization's were only performed in patients undergoing right-sided resections.

\section{Short-term outcomes (Table 2)}

Overall morbidity occurred in $63(83 \%)$ out of 76 patients undergoing left sided-resections compared to $74(73 \%)$ out of 102 patients undergoing right sided-resections $(\mathrm{P}=0.105)$, 
Table 2 Short-term outcomes after left or right liver resection for suspected PHC

\begin{tabular}{|c|c|c|c|c|}
\hline Outcome & $\begin{array}{l}\text { All suspected } \\
\text { PHC }(n=178)\end{array}$ & $\begin{array}{l}\text { Left-sided liver } \\
\text { resection }(n=76)\end{array}$ & $\begin{array}{l}\text { Right-sided liver } \\
\text { resection }(n=102)\end{array}$ & $P$ value \\
\hline Hospital stay, median [IQR] & $13[9-21]$ & 13 [9-22] & $13[8-21]$ & 0.909 \\
\hline Overall morbidity, $\mathrm{n}[\%]$ & $137[77]$ & 63 [83] & 74 [73] & 0.105 \\
\hline Severe morbidity, $\mathrm{n}[\%](C D$ grade $\geq 3$ ) & $103[58]$ & $41[54]$ & 62 [61] & 0.361 \\
\hline Posthepatectomy haemorrhage (ISGLS B or C), n [\%] & $14[8]$ & $5[7]$ & 9 [9] & 0.582 \\
\hline Bile leakage (ISGLS B or C), $\mathrm{n}$ [\%] & $57[32]$ & $26[34]$ & $31[30]$ & 0.589 \\
\hline HJ-leakage, n [\%] & $32[18]$ & $16[21]$ & $16[16]$ & 0.462 \\
\hline
\end{tabular}

$\mathrm{PHC}$, perihilar cholangiocarcinoma.

whilst severe morbidity occurred in 54\% versus $61 \%$, respectively, $\mathrm{P}=0.361$. Ninety-day mortality of all patients with suspected PHC was $14 \%$ (24 out of 178 ), with $11 \%$ 90 -day mortality in the left-sided group ( 8 out of 76 ) compared to $16 \%$ the right-sided group (16 out of 102 ). Although 90-day mortality was higher after right-sided resection, this difference was not statistically significant $(\mathrm{P}=0.319)$. Also, no significant difference was observed between patients with or without extended resections ( $19 \%$ versus $11 \%, \mathrm{P}=0.199)$. The incidence of liver failure was $11 \%$ (8 out of 76 ) after left hemihepatectomy and $22 \%$ (22 out of 102) after right hemihepatectomy $(\mathrm{P}=0.052)$. After left-sided resection there were 16 patients with hepaticojejunostomy leakage (21\%) compared to 16 out of 102 patients (16\%) undergoing right-sided resection $(\mathrm{P}=0.462)$. The proportion of patients with $\mathrm{R} 0$ resections, revised according to ICCR guidelines (17), was comparable in both groups; $40 \%$ and $39 \%$ in left- and right-sided resections, respectively $(\mathrm{P}=0.849)$. Table $\mathrm{S} 1$ shows separate outcomes for left hepatectomy, extended left hepatectomy, right hepatectomy and extended right hepatectomy, respectively. Here, there was a significant difference in (grade b or c) biliary leakage, most observed after extended left hepatectomy (6 out of 8 patients, $75 \%$ ) undergoing extended left hepatectomy. Again, no significant differences in outcomes were observed.

\section{Long-term outcomes}

For long-term outcomes, 149 patients with pathologically proven PHC [excluding intraductal papillary neoplasms of the bile duct (IPNB) without invasion, $n=8$ ] were analysed. The reverse Kaplan-Meier estimate of the median follow up was 5.5 years (95\% CI: 4.8-6.2 years). Recurrence after left-sided resection occurred in 22 out of 65 patients (34\%), whilst 34 out of 84 patients $(40 \%)$ undergoing right-sided resection developed recurrence during followup $(\mathrm{P}=0.407)$. Twenty-two patients with 90 -day mortality were excluded from survival analysis (2 patients with other final pathology died postoperatively), resulting in a total of 58 patients after left-sided resections and 69 patients after right-sided resection for survival analysis. Fiveyear overall survival was $43.7 \%$ after left-sided resections compared to $38.2 \%$ after right-sided resections (Figure 1), with a median overall survival of 56 versus 47 months, respectively $(\mathrm{P}=0.553)$. Univariate and multivariate Cox-regression analysis for overall survival (excluding postoperative mortality) showed that only ASA classification $\geq 3$ independently predicted survival, whilst PVR and leftsided resections were not independent predictors of worse survival (Table S2).

\section{Portal vein reconstructions}

In Table S3, baseline characteristics and short-term outcomes of patients undergoing hemihepatectomy with concomitant PVR ( $n=42)$ are compared to those who had no PVR ( $\mathrm{n}=136)$. Differences were observed in the number of extended resections; 38 out of 136 patients without PVR (28\%) compared to 23 out of 42 patients with PVR (55\%) 


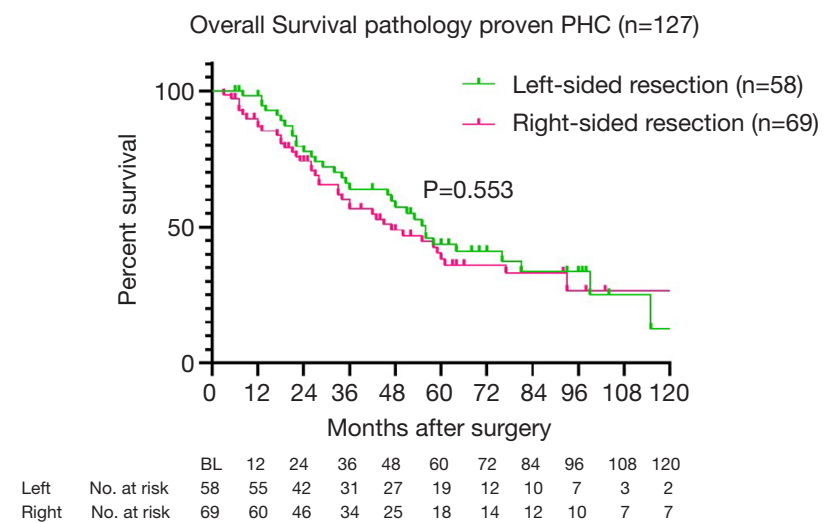

Figure 1 Overall survival of patients with pathologically proven PHC, excluding patients with postoperative mortality: leftsided resection (green) versus right-sided resection (pink). PHC, perihilar cholangiocarcinoma.

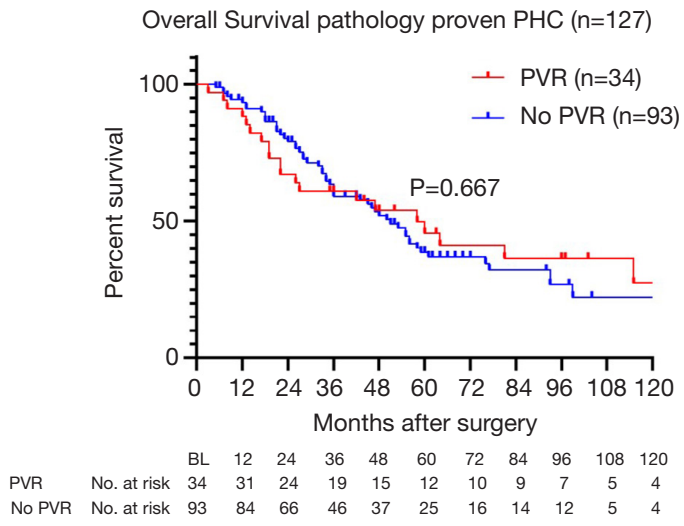

Figure 2 Overall survival of patients with pathologically proven PHC, excluding patients with postoperative mortality: portal vein reconstructions (red) versus no portal vein reconstruction (blue). $\mathrm{PHC}$, perihilar cholangiocarcinoma.

underwent extended resection $(\mathrm{P}=0.001)$. Also, the median tumor diameter was $33 \mathrm{~mm}$ (IQR, 25-45 mm) in patients with PVR compared to $28 \mathrm{~mm}$ (IQR, 20-40 mm) in patients without PVR ( $\mathrm{P}=0.032)$. Although overall and severe morbidity and 90-day mortality were comparable in both groups (Table S3), post-hepatectomy (ISGLS B or C) liver failure and haemorrhage were more frequently observed among patients undergoing concomitant PVR: 13 (31\%) and 7 (17\%) out of 42 patients, respectively, compared to 17 (13\%) and 7 (5\%) out of 136 patients without PVR $(\mathrm{P}=0.005$ and $\mathrm{P}=0.015$, respectively).
Five-year overall survival of patients with pathologically proven PHC (excluding postoperative mortality) was $45.6 \%$ for patients with PVR compared to $38.7 \%$ without PVR. Figure 2 shows survival curves of both groups, with a median overall survival of 51 months for patients with PVR versus 58 months for patients without PVR ( $\mathrm{P}=0.667)$. Recurrence was observed in 18 out of 42 patients (43\%) with PVR, compared to 40 out of 107 patients (35\%) without PVR $(\mathrm{P}=0.394)$.

\section{Discussion}

As the information available in literature on outcomes after right-sided and left-sided resections is limited and conflicting, this is the largest series comparing shortand long-term outcomes of patients undergoing leftsided or right-sided resection for (suspected) PHC. Short-term outcomes, including overall morbidity, severe morbidity, mortality and specific complications, were comparable in both groups. The incidence of liver failure was higher after right-sided resections (22\%) compared to left-sided resections (11\%). Regarding concomitant PVR, no difference in the proportion of patients undergoing concomitant PVR combined with left or right hemihepatectomy was observed. Comparison of shortterm outcomes of patients undergoing PVR to those who did not, revealed more post-hepatectomy liver failure (31\% versus $13 \%)$ and haemorrhage (17\% versus $5 \%$ ) among patients with PVR compared to patients without PVR. No difference was observed in overall survival after right-sided versus left-sided resections, as well as after resections with PVR or without PVR. The decisive factor is to achieve R0 resection and the choice whether this is to be obtained by a right-sided or left-sided resection, depends on the tumor predominantly infiltrating into the right or left part of the biliary system and liver parenchyma.

The study by Ratti and colleagues is the only one describing a survival benefit for patients undergoing right hemihepatectomy compared to patients undergoing left hemihepatectomy. Higher mortality and morbidity were reported after right-sided resection $(n=61)$, whilst the 5 -year survival year rate was higher compared to left-sided resections $(\mathrm{n}=44)$. This difference might be explained by the difference in R0-rate achieved in over $75 \%$ of the 61 patients undergoing right-sided resection compared to $61 \%$ of the 44 patients undergoing left-sided resection. Also, perineural invasion, lymphatic invasion and microvascular 
invasion were significantly more frequent in the group undergoing left-sided resection, which may also have contributed to worse survival in this group (5).

Govil and colleagues reported on their approach to offer patients with type IIIb and IV tumors left liver resection rather than extended right hemihepatectomy. Similar survival of patients undergoing left and right-sided resections was observed, as in the present study. Although this study only included 36 patients, a higher incidence of postoperative liver dysfunction was observed among 13 patients with right hemihepatectomy (5 out of 13 ) compared to 23 patients with left hemihepatectomy (0 out 23) $(\mathrm{P}=0.003)$, whilst severe complications (Clavien-Dindo grade $\geq 3$ ) occurred in $69 \%$ after right-sided resection and $43 \%$ after left-sided resection ( $\mathrm{P}=0.177$ ) (3). Conversely, Lee et al. (4) showed more severe complications (Clavien-Dindo grade $3 \mathrm{~A}$ or higher) after left-sided resection $(34.3 \%)$ for type III tumors compared to right-sided resection (10.7\%) $(\mathrm{P}=0.002)$. In the latter study, again, survival was comparable between 102 patients with Bismuth-Corlette type IIIa undergoing right-side resections (5 y OS 33\%) compared to 35 patients with type IIIb undergoing left-side resections (5 y OS 35\%). Only patients with Bismuth-Corlette type III were included in this study, and the rate of R0-resections was comparable in both groups $(82.5 \%$ right-sided group and $85.7 \%$ left-sided group) (4). Our reported R0-resection rate is lower compared to the R0-resection rates reported in literature, possibly due to our recent efforts to revise all pathology reports according to most recent guidelines. This action resulted in reclassification of residual disease based on a margin of $<1 \mathrm{~mm}$ classified as R1, including all (circumferential, periductal dissection) planes (18).

Although survival benefits of standard PVR along with right hemihepatectomy have been suggested (19), the policy in our unit is to perform PVR selectively only when the vein is directly involved. Outcomes after selective PVR are also controversial; in a meta-analysis performed in 2012 there were nine studies reporting on mortality of which two showed a higher risk of postoperative mortality after PVR while seven did not. Although in our study the liver failure rate was higher after PVR compared to no PVR, the meta-analysis including all five studies reporting on post-hepatectomy liver failure showed no significant differences between patients undergoing resection with or without PVR (11).

To answer the question whether PVR should preferably be performed with left- or right-sided hepatectomy, a study published in 2019 compared outcomes of concomitant PVR combined with right-sided hepatectomy $(\mathrm{n}=45)$ or left-sided hepatectomy $(\mathrm{n}=36)$. The authors concluded that although perioperative morbidity and mortality were higher after right-sided than after left-sided resections, comparable survival suggested that PVR can be safely combined with left-sided resections (20).

The results of the present study should be interpreted in light of several shortcomings. First, the retrospective design and the wide time-frame in which patients were treated. Several improvements have been made in treatment of patients with $\mathrm{PHC}$, potentially influencing results over time. Because PVE is mainly performed in patients undergoing right-sided resections, subsequent improvements in liver failure and mortality may have influenced the comparison of right-sided and left-sided resections. Univariate and multivariate cox regression analysis performed in this study, showed that no other factors but ASA classification 3 or 4 independently predicted survival. This analysis should be performed in a larger cohort to accurately investigate determinants for survival in this population, for example in a multicentre combined cohort such as coordinated by the International Registry of the Perihilar Cholangiocarcinoma Collaboration Group (21).

In conclusion, this study showed no significant differences in both short- and long-term outcomes in patients undergoing left- or right-sided resections for PHC. Post-hepatectomy liver failure was more frequently observed after right-sided resection (22\%) compared to left-sided resection $(11 \%)$. With the increasing use of PVE, mainly in patients undergoing right-sided resections, the occurrence of liver failure after right hemihepatectomy is likely to decrease.

\section{Acknowledgments}

Funding: None.

\section{Footnote}

Reporting Checklist: The authors have completed the STROBE reporting checklist. Available at https://hbsn. amegroups.com/article/view/10.21037/hbsn-19-948/rc

Data Sharing Statement: Available at https://hbsn. amegroups.com/article/view/10.21037/hbsn-19-948/dss

Conflicts of Interest: All authors have completed the ICMJE 
uniform disclosure form (available at https://hbsn. amegroups.com/article/view/10.21037/hbsn-19-948/coif). $\mathrm{TMvG}$ serves as an unpaid editorial board member of Hepatobiliary Surgery and Nutrition. The other authors have no conflicts of interest to declare.

Ethical Statement: The authors are accountable for all aspects of the work in ensuring that questions related to the accuracy or integrity of any part of the work are appropriately investigated and resolved. The study was conducted in accordance with the Declaration of Helsinki (as revised in 2013). The Institutional Medical Ethics Committee waived the need for individual informed consent and ethical approval (W19_408).

Open Access Statement: This is an Open Access article distributed in accordance with the Creative Commons Attribution-NonCommercial-NoDerivs 4.0 International License (CC BY-NC-ND 4.0), which permits the noncommercial replication and distribution of the article with the strict proviso that no changes or edits are made and the original work is properly cited (including links to both the formal publication through the relevant DOI and the license). See: https://creativecommons.org/licenses/by-nc-nd/4.0/.

\section{References}

1. Franken LC, Schreuder AM, Roos E, et al. Morbidity and mortality after major liver resection in patients with perihilar cholangiocarcinoma: A systematic review and meta-analysis. Surgery 2019;165:918-28.

2. Khan AS, Dageforde LA. Cholangiocarcinoma. Surg Clin North Am 2019;99:315-35.

3. Govil S, Bharatan A, Rammohan A, et al. Liver resection for perihilar cholangiocarcinoma - why left is sometimes right. HPB (Oxford) 2016;18:575-9.

4. Lee Y, Choi D, Han S, et al. Comparison analysis of leftside versus right-side resection in bismuth type III hilar cholangiocarcinoma. Ann Hepatobiliary Pancreat Surg 2018;22:350-8.

5. Ratti F, Cipriani F, Piozzi G, et al. Comparative Analysis of Left- Versus Right-sided Resection in Klatskin Tumor Surgery: can Lesion Side be Considered a Prognostic Factor? J Gastrointest Surg 2015;19:1324-33.

6. Hosokawa I, Shimizu H, Yoshitomi H, et al. Outcomes of left trisectionectomy and right hepatectomy for perihilar cholangiocarcinoma. HPB (Oxford) 2019;21:489-98.

7. Jo HS, Kim DS, Yu YD, et al. Right-side versus left-side hepatectomy for the treatment of hilar cholangiocarcinoma: a comparative study. World J Surg Oncol 2020;18:3.

8. Hirose T, Igami T, Ebata T, et al. Surgical and Radiological Studies on the Length of the Hepatic Ducts. World J Surg 2015;39:2983-9.

9. Dumitraşcu T, Stroescu C, Brasoveanu V, et al. Curativeintent Surgery for Perihilar Cholangiocarcinoma with and without Portal Vein Resection - A Comparative Analysis of Early and Late Outcomes. Chirurgia (Bucur) 2017;112:308-19.

10. Hoffmann K, Luible S, Goeppert B, et al. Impact of portal vein resection on oncologic long-term outcome in patients with hilar cholangiocarcinoma. Surgery 2015;158:1252-60.

11. Chen W, Ke K, Chen YL. Combined portal vein resection in the treatment of hilar cholangiocarcinoma: a systematic review and meta-analysis. Eur J Surg Oncol 2014;40:489-95.

12. de Castro SM, Kuhlmann KF, Busch OR, et al. Incidence and management of biliary leakage after hepaticojejunostomy. J Gastrointest Surg 2005;9:1163-71; discussion 1171-3.

13. Rassam F, Roos E, van Lienden KP, et al. Modern work-up and extended resection in perihilar cholangiocarcinoma: the AMC experience. Langenbecks Arch Surg 2018;403:289-307.

14. Koch M, Garden OJ, Padbury R, et al. Bile leakage after hepatobiliary and pancreatic surgery: a definition and grading of severity by the International Study Group of Liver Surgery. Surgery 2011;149:680-8.

15. Rahbari NN, Garden OJ, Padbury R, et al. Posthepatectomy liver failure: a definition and grading by the International Study Group of Liver Surgery (ISGLS). Surgery 2011;149:713-24.

16. Rahbari NN, Garden OJ, Padbury R, et al. Posthepatectomy haemorrhage: a definition and grading by the International Study Group of Liver Surgery (ISGLS). HPB (Oxford) 2011;13:528-35.

17. Burt $\mathrm{AD}$, Alves V, Bedossa $\mathrm{P}$, et al. Data set for the reporting of intrahepatic cholangiocarcinoma, perihilar cholangiocarcinoma and hepatocellular carcinoma: recommendations from the International Collaboration on Cancer Reporting (ICCR). Histopathology 2018;73:369-85.

18. Roos E, Franken LC, Soer EC, et al. Lost in translation: confusion on resection and dissection planes hampers the interpretation of pathology reports for perihilar cholangiocarcinoma. Virchows Arch 2019;475:435-43. 19. Neuhaus P, Thelen A, Jonas S, et al. Oncological superiority 
of hilar en bloc resection for the treatment of hilar cholangiocarcinoma. Ann Surg Oncol 2012;19:1602-8.

20. Bednarsch J, Czigany Z, Lurje I, et al. Left- versus rightsided hepatectomy with hilar en-bloc resection in perihilar cholangiocarcinoma. HPB (Oxford) 2020;22:437-44.

Cite this article as: Franken LC, Olthof PB, Erdmann JI, van Delden OM, Verheij J, Besselink MG, Busch OR, van Gulik TM. Short- and long-term outcomes after hemihepatectomy for perihilar cholangiocarcinoma: does left or right side matter? HepatoBiliary Surg Nutr 2021;10(2):154-162. doi: 10.21037/ hbsn-19-948
21. Olthof PB, Aldrighetti L, Alikhanov R, et al. Portal Vein Embolization is Associated with Reduced Liver Failure and Mortality in High-Risk Resections for Perihilar Cholangiocarcinoma. Ann Surg Oncol 2020;27:2311-8. 


\section{Supplementary}

Table S1 Short-term outcomes after left and right hepatectomy and trisectionectomy for suspected PHC

\begin{tabular}{|c|c|c|c|c|c|}
\hline Outcome & $\begin{array}{l}\text { Left } \\
\text { hepatectomy } \\
(n=68)\end{array}$ & $\begin{array}{c}\text { Left } \\
\text { trisectionectomy } \\
(\mathrm{n}=8)\end{array}$ & $\begin{array}{c}\text { Right } \\
\text { hepatectomy } \\
(n=49)\end{array}$ & $\begin{array}{c}\text { Right } \\
\text { trisectionectomy } \\
(\mathrm{n}=53)\end{array}$ & $P$ value \\
\hline Overall morbidity, n [\%] & $56[82]$ & $7[88]$ & $37[76]$ & 37 [70] & 0.361 \\
\hline Severe morbidity, $\mathrm{n}[\%],(\mathrm{CD}$ grade $\geq 3$ ) & $34[50]$ & $7[88]$ & 32 [65] & $30[57]$ & 0.124 \\
\hline Posthepatectomy liver failure (ISGLS B or C), n [\%] & $6[9]$ & $2[25]$ & $9[18]$ & 13 [25] & 0.121 \\
\hline Posthepatectomy haemorrhage (ISGLS B or C), n [\%] & $4[6]$ & $1[13]$ & $4[8]$ & 5 [9] & 0.851 \\
\hline Bile leakage (ISGLS B or C), n [\%] & 20 [29] & $6[75]$ & $18[37]$ & $13[25]$ & 0.031 \\
\hline HJ-leakage, $n$ & 13 & 3 & 7 & 10 & 0.450 \\
\hline
\end{tabular}

ISGLS, International Study Group of Liver Surgery (ISGLS); PHC, perihilar cholangiocarcinoma.

Table S2 Univariate and multivariate Cox regression analysis

\begin{tabular}{|c|c|c|c|c|c|c|}
\hline Variable & \multicolumn{3}{|c|}{ Univariate analysis } & \multicolumn{3}{|c|}{ Multivariate analysis } \\
\hline Age $>65$ & 0.881 & $0.550-1.412$ & 0.599 & & & \\
\hline$A S A \geq 3$ & 1.886 & $1.032-3.445$ & 0.039 & 1.910 & $1.001-3.645$ & 0.050 \\
\hline Bismuth-Corlette type IV & 1.119 & $0.625-2.005$ & 0.705 & & & \\
\hline Extended resection & 0.950 & $0.581-1.553$ & 0.838 & & & \\
\hline ECOG performance state 2 or 3 & 1.307 & $0.565-3.026$ & 0.531 & & & \\
\hline \multicolumn{7}{|l|}{ Biliary drainage } \\
\hline None & Ref & - & 0.459 & & & \\
\hline Both & 0.477 & $0.166-1.373$ & 0.170 & & & \\
\hline Preoperative cholangitis & 1.586 & $0.993-2.532$ & 0.053 & 1.357 & $0.826-2.228$ & 0.228 \\
\hline Portal vein reconstruction & 1.077 & $0.732-1.584$ & 0.707 & 1.130 & $0.744-1.716$ & 0.566 \\
\hline Perineural growth & 1.245 & $0.496-3.126$ & 0.641 & & & \\
\hline Vasoinvasiveness & 1.556 & $0.798-3.037$ & 0.195 & * & & \\
\hline Poor differentiation & 0.959 & $0.550-1.669$ & 0.881 & & & \\
\hline Stage III or IV & 1.416 & $0.892-2.249$ & 0.140 & 1.356 & $0.836-2.198$ & 0.217 \\
\hline $\mathrm{R} 1$ resection & 1.076 & $0.675-1.715$ & 0.757 & & & \\
\hline
\end{tabular}

*, not included in multivariate analysis due to high number of missing values. ASA, Amercian Society of Anaesthesiologists. 
Table S3 Baseline characteristics and short-term outcomes for patients with and without concomitant portal vein reconstruction for suspected $\mathrm{PHC}$

\begin{tabular}{|c|c|c|c|}
\hline Variable & No PVR [n=136] & $P V R[n=42]$ & $P$ value \\
\hline Female, n [\%] & $55[60]$ & 14 [33] & 0.409 \\
\hline Age, mean [SD] & $63[11]$ & $62[9]$ & 0.458 \\
\hline ASA, n [\%] & & & 0.490 \\
\hline 1 & 26 [19] & $8[19]$ & \\
\hline II & 87 [64] & 30 [71] & \\
\hline III & $23[17]$ & $4[10]$ & \\
\hline ECOG performance state, $\mathrm{n}$ [\%] & & & 0.125 \\
\hline 0 & 99 [73] & $23[55]$ & \\
\hline 1 & 27 [20] & $15[36]$ & \\
\hline 2 & $9[7]$ & $3[7]$ & \\
\hline 3 & $1[1]$ & $1[2]$ & \\
\hline Tumor diameter, median [IQR] & 27 [20-40] & 33 [25-45] & 0.032 \\
\hline Bismuth-Corlette type, n [\%] & $N=134$ & $\mathrm{~N}=42$ & \\
\hline I & $1[1]$ & 0 & 0.574 \\
\hline II & $3[2]$ & 0 & 0.328 \\
\hline Illa & $70[52]$ & $24[57]$ & 0.578 \\
\hline IIllb & $41[31]$ & $8[19]$ & 0.145 \\
\hline IV & 19 [14] & $10[24]$ & 0.142 \\
\hline Drainage method, n [\%] & & & 0.031 \\
\hline None & 26 [19] & $3[7]$ & 0.066 \\
\hline Endoscopic & $67[49]$ & $17[41]$ & \\
\hline Percutaneously & $11[8]$ & $4[10]$ & \\
\hline Both & $31[23]$ & $18[43]$ & \\
\hline Preoperative cholangitis, $\mathrm{n}$ [\%] & $50[37]$ & $17[41]$ & 0.664 \\
\hline Portal vein embolization, $\mathrm{n}$ [\%] & 17 [13] & $7[17]$ & 0.490 \\
\hline Extended resection, $\mathrm{n}$ [\%] & $38[28]$ & $23[55]$ & 0.001 \\
\hline Final pathology, n [\%] & & & $<0.001$ \\
\hline $\mathrm{PHC}$ & $107[79]$ & $42[100]$ & \\
\hline Other & 29 [21] & 0 & \\
\hline Hospital stay, median [IQR] & $13[8-21]$ & $13[10-26]$ & 0.943 \\
\hline Overall morbidity, n [\%] & $101[74]$ & $36[86]$ & 0.123 \\
\hline Severe morbidity (CD grade $\geq 3$ ), $n$ [\%] & $78[57]$ & $25[59]$ & 0.803 \\
\hline 90-day mortality, n [\%] & 16 [12] & $8[19]$ & 0.227 \\
\hline Posthepatectomy liver failure (ISGLS B or C), n [\%] & $17[13]$ & $13[31]$ & 0.005 \\
\hline Posthepatectomy haemorrhage (ISGLS B or C), n [\%] & $7[5]$ & $7[17]$ & 0.015 \\
\hline Bile leakage (ISGLS B or C), n [\%] & 44 [32] & $13[31]$ & 0.865 \\
\hline HJ-leakage & 26 [19] & $6[14]$ & 0.655 \\
\hline
\end{tabular}

PHC, perihilar cholangiocarcinoma; VR, portal vein resection; ISGLS, International Study Group of Liver Surgery (ISGLS); ASA, Amercian Society of Anaesthesiologists. 